GLOBAL JOURNAL OF COMMUNITY MEDICINE VOL. 2 NO. 1 \& 2 2009: 1 - 4 COPYRIGHTৎ BACHUDO SCIENCE CO. LTD PRINTED IN NIGERIA. ISSN 1597 - 9857

\title{
PRACTICE OF ANTENATAL CLINICAL BREAST EXAMINATION IN CALABAR
}

\author{
A. UDO., M. EKOTT., E. E. EFIOK., E. EKANEM. AND E. UDOMA
}

(Received 28 July, 2008; Revision Accepted 16 September, 2008)

\begin{abstract}
Reports of a rising incidence of breast cancer and the consistent finding of a significantly younger population of breast cancer patients in the country than in the west led to this study to determine the proportion of women who have a clinical breast examination at the booking visit for antenatal care in the University of Calabar Teaching Hospital (UCTH).The booking information on the antenatal cards of patients who registered within a one-month period was examined. Clinical breast examination (CBE) was performed on $41.6 \%$ of the women. Women who were reviewed by consultants recorded a rate of $78.2 \%$ while the rates for women attended to by resident doctors and interns were $41.2 \%$ and $19.6 \%$ respectively $(P=0.00)$. The $C B E$ rate was $57.6 \%$ among women who were reviewed by female physicians and $38.3 \%$ among those reviewed by male physicians $(P=0.00)$. The practice of CBE in $\mathrm{UCTH}$ is low and is significantly related to the cadre and gender of the attending physician. Obstetricians must embrace the practice fully and utilize measures such as increased supervision and departmental seminars to sensitize doctors they train to emulate them.
\end{abstract}

KEYWORDS: Antenatal, Practice and Breast Examination

\section{INTRODUCTION}

Breast Cancer is one of the two leading causes of female malignancy death in Nigeria (Ajayi 2002). The incidence is increasing at an alarming rate with a $100 \%$ rise from 13.8-15.3/ 100,000 women in 1980 to $116 / 100,000$ women in 2001 (Adebamowo and Ajayi 2000). The fiveyear survival rate of patients in the country is less than $10 \%$ as against more than $70 \%$ in western countries (Okobia et al 2006). The remarkable survival rates in these nations are attributable to their screening programs which encourage early detection of premalignant and malignant lesions (Peto et al 2000). Breast examination by a physician otherwise known as clinical breast examination (CBE) is one of the measures adopted in such programs. In Nigeria as with many other developing countries, there are no such national programs. As a result, more than two-thirds of patients present in hospital with advanced disease (Okobia et al 2006, Ihekwaba 1993, Anyawu 2000, Adesunkanmi et al 1999).
The lack of an organized screening program in the country has raised the need for opportunistic screening during health care encounters for other reasons (Smith et al 2002, USAID 2005). In developing nations, most healthy women only visit health facilities for physical examination during pregnancy (Kauser 2004). It has also been estimated that $3 \%$ of breast cancers occur in pregnancy (Rao et al 2001). The rate in the country may be higher since the peak age is at least a decade earlier than for Caucasians and significantly more patients fall within the reproductive age range (Anyawu 2000, Adesunkanmi et al 1999, Nggada et al 2008, Adebamwo 1998, ljaduola and Smith 1998). The routine practice of antenatal CBE at the booking visit is therefore important in our setting. The extent of this practice in our centre has not yet been assessed. Hence, this study aims to determine the proportion of women who have a CBE on booking for antenatal care at the University of Calabar Teaching Hospital (UCTH). It is hoped that the findings of this audit will

A. Udo, Dept. of Obstetrics and Gynaecology, Univ. of Calabar Teaching Hospital, Calabar, Nigeria

M. Ekott, Dept. of Obstetrics and Gynaecology, Univ. of Calabar Teaching Hospital, Calabar, Nigeria

E. E. Efiok, Dept. of Obstetrics and Gynaecology, Univ. of Calabar Teaching Hospital, Calabar, Nigeria

E. Ekanem, Dept. of Obstetrics and Gynaecology, Univ. of Calabar Teaching Hospital, Calabar, Nigeria

E. Udoma, Dept. of Obstetrics and Gynaecology, Univ. of Calabar Teaching Hospital, Calabar, Nigeria 
encourage and entrench the culture of CBE in all doctors who train in the maternity unit. This will result in early detection and treatment of suspicious breast lesions in our women with possible good prognosis.

\section{PATIENTS AND METHOD}

Case notes of women who booked for antenatal care in UCTH between 7th February, 2007 and $7^{\text {th }}$ March, 2007 were retrieved for the study. The booking information on each antenatal card was scrutinized to determine the cadre and gender of the doctor who attended to the woman and to note if physical examination of the breasts was part of this assessment. The proportion of women who had a CBE and those who had none and the proportion of doctors of each cadre and gender who attended to each of the two groups of women were compared using chi-square tests.

\section{RESULT}

Four hundred and twenty-four women booked to receive antenatal care during the study period and $413(97.4 \%)$ case notes were available for the study. Breast examination was performed on only $172(41.6 \%)$ of the women, while $241(58.4 \%)$ had no CBE. Seven women had a past surgical history of breast lump removal. Of this number, two $(28.6 \%)$ had a CBE. Table 1 compares the rate of performance of CBE by the various cadres of doctors who attended to the women. Of the 107 women who were reviewed by interns, 21 (19.6\%) had CBE while CBE was performed on $94(41.2 \%)$ of the 228 women reviewed by resident doctors and 61 $(78.2 \%)$ of the 78 women attended to by consultants. There was a significant association between the cadre of the attending physician and the rate of performance of CBE $(P=0.00)$. Table 2 on the gender of the physician and the rate of CBE shows that female physicians performed $\mathrm{CBE}$ on $57.6 \%$ of patients they reviewed, significantly higher than $38.3 \%$ recorded for patients reviewed by male physicians $(P=0.00)$.

Table 1: The Rate of CBE among patients reviewed by each cadre of physicians

\begin{tabular}{|c|c|c|c|}
\hline Cadre & $\begin{array}{l}\text { No of women who } \\
\text { had CBE (\%) }\end{array}$ & $\begin{array}{l}\text { No of women who } \\
\text { had no CBE (\%) }\end{array}$ & Total (\%) \\
\hline Interns & $21(19.6)$ & $86(80.4)$ & 107(100) \\
\hline Residents & $94(41.2)$ & $134(58.8)$ & $228(100)$ \\
\hline Consultants & 61 (78.2) & $17(21.8)$ & 78 (100) \\
\hline Total & $176(42.6)$ & 237(57.4) & $413(100)$ \\
\hline
\end{tabular}

Table 2: The Rate of CBE among patients reviewed by Male and Female Physicians

\begin{tabular}{lll}
\hline Gender & $\begin{array}{l}\text { No of women who } \\
\text { had CBE (\%) }\end{array}$ & No of women who had \\
& no CBE (\%)
\end{tabular}

\begin{tabular}{lrcr}
\hline Male & $123(38.3)$ & $198(61.7)$ & $321(100)$ \\
Female & $53(57.6)$ & $39(42.4)$ & $92(100)$ \\
Total & $\mathbf{1 7 6 ( 4 2 . 6 )}$ & $\mathbf{2 3 7 ( 5 7 . 4 )}$ & $\mathbf{4 1 3 ( \mathbf { 1 0 0 } )}$ \\
\hline & $\mathrm{X}^{2}=10.88$ & $\mathrm{df}=1$ & $\mathrm{P}=0.00$
\end{tabular}

\section{DISCUSSION}

The study revealed that less than half of the women who booked for antenatal care during the period had a CBE. It is also important to note that CBE was performed on only 2 of the 7 patients documented by the nurses as having had a past history of breast lump removal. Although it is common knowledge that in the country patients are frequently lost to follow up after surgery, the attending physicians overlooked the need to exclude a possible recurrence of a premalignant or malignant lump. A worse situation seems to exist in southeastern Nigeria as a study also conducted in a tertiary health facility reported that only $3 \%$ of antenatal clinic attendees had a CBE (Onwere et al 2008).

Women who were reviewed by consultants recorded a CBE rate of $78 \%$ while the rates for women attended to by resident 
doctors and interns were $41 \%$ and $20 \%$ respectively. These findings suggest that not only have obstetricians not fully imbibed the practice of antenatal CBE; those who have are yet to impart the practice to doctors under their supervision. This is cause for concern as the hospital is an academic centre and obstetrics and gynaecology is a specialty that caters to the health needs of women. There is need for regular departmental seminars on breast cancer to heighten the awareness of doctors on its increasing incidence in the country and to remind them of the preventive strategies to reduce mortality. Strategically placed posters in consulting rooms would also serve as useful reminders to physicians to perform CBEs (Gorin et al 2006).

The study also noted that the women who were reviewed by female physicians recorded a higher rate of CBEs than those who were seen by male physicians. This is similar to the report of a study conducted in Minnesota (Lurie et al 1993). Another study seeking to explain the Minnesota finding revealed that female physicians feel more personal responsibility for ensuring that patients receive breast cancer screening and are more comfortable in performing breast examinations (Lurie et al 1997). Regular departmental seminars on breast cancer are again important in this regard. Not only would subtopics which specifically address this issue help to narrow the gender gap, the seminars would also enhance breast health awareness among nurses in the department. A nurse acting as chaperone (a regular role nurses play in the antenatal clinics) who is breast health aware is more likely to notice and remind the physician to perform a CBE should he forget. Such a nurse will also be more committed to educating women on breast health awareness during the routine health talks thus empowering them to request for CBE when examined by the physician.

\section{CONCLUSION}

The level of practice of antenatal CBE in $\mathrm{UCTH}$ is low and a wide gap exists between the level of practice by consultants and doctors they supervise and among female physicians and their male colleagues. The lack of a national screening program has resulted in most women who present at the antenatal clinics not having ever been examined for suspicious breast lesions. There is therefore the need for obstetricians to fully embrace the practice of antenatal CBE and initiate measures to ensure that all doctors training under them are adequately sensitized to do same. This will ensure that every woman who registers for antenatal care at the UCTH has this additional health benefit.

\section{REFERENCES}

Adebamwo, C. A., 1998. Breast cancer in Nigeria: An Overview. Paper presented at the $4^{\text {th }}$ annual convention of the Association of Nigerian Physicians in the Americas. Orlando, Florida,

Adebamowo, C. A, and Ajayi, O. O., 2000. Breast cancer in Nigeria. West Afr J Med. 19 (3): 179-91

Adesunkanmi, A. R., Lawal, O. O., Adelusola, K. A. and Durosimi, M. A., 1999. The severity, outcome and challenges of breast cancer in Nigeria. Br. J. Surg. 86 (5) 665-8.

Ajayi, I. O., 2002. Breast and cervical cancer screening among family physicians in Nigeria. Afr J Med Sci. 31 (4): 305-9

Anyawu, S. N., 2000. Breast cancer in eastern Nigeria: a ten-year review. West Afr J Med. 19 (2): 120-5.

Gorin, S. S, Ashford MD, Lantigua R, Hossain A et al. 2006. Effectiveness of academic detailing on breast cancer screening among primary care physicians in an underserved community. The Journal of the American Board of Family Medicine 19: 110-121.

Ihekwaba, F. N., 1993. Breast cancer in Nigerian Women. Br J Surg. Jan; 80 (1): 126.

ljaduola, T. G. and Smith, E. B., 1998. Pattern of breast cancer among White American, African-American and non-immigrant West African women. J Natl Med Assoc.; 90 (9): 547-51.

Kausar, R., 2004. Antenatal care. Indian journal for the practicing doctor. 2004; 1 (1): 910

Lurie, N, Slather, J, McGovern, P., et al., 1993. Preventive care for women - Does sex of 
the physician matter? The New England Journal of Medicine 329 (7) 478-482.

Lurie, N., Margolis, K. L, McGovern, P.G, Mink, P. J, Slater, S.J., 1997. Why do patients of female physicians have higher rates of breast and cervical cancer screening? J Gen Intern Med. 12 (1): 34-43.

Nggada, H. A, Yawe, K. D, Abdulazeez, J, Khalil, M. A., 2008. Breast cancer burden in Maiduguri, Northeastern Nigeria. Breast J. 14(3): 284-6.

Okobia, M. N., Bunker, C.H, Okonofua, F., Osime, U., 2006. Knowledge, attitude and practice of Nigerian women towards breast cancer. World J Surg Oncol. 4: 11.

Onwere, S., Okoro, O., Chigbu, B. and Onwere, A., 2008. Practice of antenatal clinical breast examination as a method of early detection of breast cancer by healthcare providers in a low resource setting. Arch Gynechol Obstet. 278 (2): 115-7.

Peto, R., Boreham, J., Clark, M., Davies, C. and Beral, V., 2000. UK and USA breast cancer deaths down $25 \%$ in year 2000 at ages 20-69 years. Lancet 355:1822.

Rao, A. A., Saini, A. S. and Chatterjee, A., et al., 2001. Malignant disease: medical management and pregnancy In: Medical Disorders in Pregnancy. Pankaj D, Purvi $P$ (Eds). Jaypee Brothers Medical Publishers (P) Ltd.; New Delhi: 33-41.

Smith, R. A., Calef, M., Albert, U., Chen, T., et al., 2002. Breast cancer in limited resource countries: early detection and access to care. The Breast Journal 12 (s1): s16-21.

USAID. Integrating breast cancer screening into FP/RH women's outreach. Private sector project for women's health. Jordan 20052010 